Pesq. Vet. Bras. 28(1):77-81, janeiro 2008

\title{
Conidiobolomicose em ovinos no Estado de Mato Grosso
}

\author{
Fabiana M. Boabaid², Eduardo V. Ferreira², Laura P. de Arruda², Naiani D. \\ Gasparetto ${ }^{2}$, Roberto L. de Souza2, Maria C. da Silva², Valéria Dutra², Luciano \\ Nakazato ${ }^{2}$ e Edson M. Colodel ${ }^{2^{*}}$
}

\begin{abstract}
Boabaid F.M., Ferreira E.V., Arruda L.P., Gasparetto N.D., Souza R.L., Silva M.C., Dutra V., Nakazato L. \& Colodel E.M. 2008. [Conidiobolomycosis in sheep in the state of Mato Grosso, Brazil.] Conidiobolomicose em ovinos no Estado de Mato Grosso. Pesquisa Veterinária Brasileira 28(1):77-81. Departamento de Clínica Médica Veterinária, Faculdade de Agronomia e Medicina Veterinária, Universidade Federal de Mato Grosso, Av. Fernando Correia da Costa s/n, Bairro Coxipó, Cuiabá, MT 78068900, Brasil. E-mail: moleta@ufmt.br

The epidemiological, clinical, pathological and mycological findings of an outbreak of conidiobolomycosis in a flock of 40 Santa Ines sheep, in the state of Mato Grosso, Brazil, are reported. The illness occurred in the municipality of Nobres during January-June, 2007 , resulting in death of about $30 \%$ of the affected sheep within 2-5 weeks. The clinical signs were characterized by apathy, weight loss, labored and noisy breathing with dyspnea, and mucous or serohemorrhagic nasal discharge. In three sheep there was unilateral exophthalmia, keratitis and corneal ulceration. A firm whitish, multi-lobulated, friable growth was evident in the ethmoturbinate region at the coronal sections of the head from six affected sheep. In all sheep the choana had similar nodular infiltration which resulted in local obstruction. In three of those there was exophthalmia. There was infiltration in the cribiform plate and brain (2 cases), regional lymph nodes (2), lungs (3), and abomasums (1). Microscopic findings were granulomatous inflammation of the rhinoetimoidal region, with necrosis, lymphocytic infiltration, epithelioid multinucleated giant cells and fibrovascular tissue, surrounding Splendore-Hoeppli material wich contained unstained ghost images of hyphae. The methenamine-silver stain uncover fungi hyphae, rarely ramified with bulbous dilatation in their extremities. Conidiobolus sp. was isolated from nasal tissue lesions of four sheep.
\end{abstract}

INDEX TERMS: Conidiobolomycosis, sheep, granulomatous rhinitis, Conidiobolus sp

RESUMO.- Relatam-se os achados epidemiológicos, clínicos, patológicos e micológicos de conidiobolomicose em ovinos no Estado de Mato Grosso. A doença ocorreu em uma propriedade no município de Nobres, em um rebanho com 40 ovelhas adultas, entre os meses de janeiro a junho de 2007. Aproximadamente $30 \%$ dos ovinos da propriedade adoeceram e todos os doentes morreram em curso clínico de 2-5 semanas. O quadro clínico foi carac-

\footnotetext{
${ }^{1}$ Recebido em 9 de outubro de 2007.

Aceito para publicação em 1 de novembro de 2007.

2 Departamento de Clínica Médica Veterinária, Faculdade de Agronomia e Medicina Veterinária, Universidade Federal de Mato Grosso, Av. Fernando Correia da Costa s/n, Bairro Coxipó, Cuiabá, MT 78068900. *Autor para correspondência: moleta@ufmt.br
}

terizado por apatia, emagrecimento, dificuldade respiratória com dispnéia, respiração ruidosa e oral, secreção nasal mucosa ou sero-sanguinolenta, exoftalmia unilateral, por vezes com cegueira, e morte. Havia desaparecimento de etmoturbinados com substituição por tecido brancacento, finamente granular, multilobulado e friável infiltrando-se na lâmina cribiforme, no septo nasal e nas coanas em todos os ovinos necropsiados. Lesões similares foram encontradas em linfonodos regionais (2 casos), pulmões (3), encéfalo (2) e em linfonodos do abomaso (1). Microscopicamente havia inflamação granulomatosa da região rinocerebral, caracterizada por necrose, proliferação de tecido conjuntivo, infiltrado de neutrófilos, eosinófilos, células epitelióides e células gigantes multinucleadas freqüentemente circundando material Splendori- 
Hoeppli, onde havia imagens negativas de hifas. $\mathrm{Na}$ impregnação pela Prata-Metenamina, as hifas tinham septos e ramificações escassas e irregulares, com dilatação balonosa terminal e com forte demarcação de contornos. Isolou-se de tecido nasal de quatro ovinos Conidiobolus sp.

TERMOS DE INDEXAÇÃO: Conidiobolomicose, ovinos, rinite granulomatosa, Conidiobolus sp.

\section{INTRODUÇÃO}

A conidiobolomicose é causada por fungos do gênero Conidiobolus, ordem Entomophtorales. O gênero Conidiobolus é frequentemente associado com rinite granulomatosa crônica no homen e nos animais (Aydogdu et al. 2001, Rane et al. 2002, Prabhu \& Patel 2004, Hoogendijk et al. 2006, Thomas et al. 2006). É um fungo saprofítico que ocorre principalmente em regiões de clima tropical e subtropical, em áreas de alta umidade, sendo encontradas como parasita de insetos, em vegetais em decomposição e no solo (Fonseca et al. 1989, Almeid \& Scully 2002). Conidiobolus coronatus, $C$. lamprageus e $C$. incongruus já foram identificados como causa de enfermidade em animais (Carrigan et al. 1992, Morris et al. 2001, Silva et al. 2007b). Duas formas clínicas da doença têm sido relacionadas com Conidiobolus em ovinos. A forma rinofacial se caracteriza por um aumento de volume no vestíbulo nasal, união mucocutânea do nariz, pele da região anterior da face e lábio superior, apresentando lesões ulceradas na mucosa nasal e no palato duro (Riet-Correa 2007, Silva et al. 2007a). A outra forma é denominada nasofaríngea, pois afeta principalmente a região etmoidal, faringe e seios paranasais, o ovino pode apresentar dispnéia, secreção nasal, respiração ruidosa, assimetria crânio-facial e exoftalmia unilateral (Riet-Correa 2007, Silva et al. 2007a). A micose nasofaríngea se caracteriza pela presença de massa nodular, com superfície granulosa, de coloração amarela ou branca com necrose da região etmoidal. A lesão se estende para os seios nasais, placa cribiforme, podendo invadir a órbita ocular e a região frontal do cérebro (Ketterer et al. 1992, Morris et al. 2001). É comum os animais apresentarem lesões invadindo os pulmões e, mais raras, nos rins, nos linfonodos, no coração, no fígado e na vesícula biliar (Carrigan et al. 1992, Silva et al. 2007b). Histologicamente há inflamação crônica granulomatosa multifocal, com centro necrótico contendo hifas largas circundadas por material Splendori-Hoeppli. Ao redor da área de necrose há proliferação de tecido fibroso com infiltrado de neutrófilos, eosinófilos, linfócitos, células epitelióides, com numerosas células gigantes multinucleadas (Morris et al. 2001, Riet-Correa 2007).

Descrevem-se os achados epidemiológicos, clínicos, patológicos e micológicos de um surto de conidiobolomicose nasofaríngea em um rebanho de ovinos no Estado de Mato Grosso.

\section{MATERIAL E MÉTODOS}

A enfermidade ocorreu no município de Nobres, MT, em uma propriedade com aproximadamente 40 ovinos adultos. $O$ histórico clínico, informações sobre o manejo nutricional e sanitário, a morbidade e a mortalidade foram obtidos com o proprietário. A doença foi observada durante o período de janeiro a julho de 2007. No total 12 ovinos foram afetados, dos quais 7 foram submetidos à avaliação clínica e após a morte espontânea, 6 foram encaminhados para o Laboratório de Patologia Veterinária (LPV) enecropsiados.

Durante a necropsia a cabeça foi aberta longitudinalmente sobre a linha mediana. Foram coletadas amostras de tecido da região etmoidal e nasofaringe, e fragmentos de pulmão, fígado, rim, coração, encéfalo e trato gastrointestinal, sendo em seguida fixados em solução formalina a $10 \%$, processados rotineiramente para estudo histológico e corados pela hematoxilina-eosina (HE) e método de prata-metanamina (GMS) (Prophet et al. 1992).

Fragmentos de pulmão, linfonodos submandibulares e massas da região da nasofaringe e do osso etmoidal de 4 ovinos foram encaminhadas ao Laboratório de Microbiologia Veterinária (LMV), Universidade Federal de Mato Grosso (UFMT). Os materiais foram lavados em solução salina estéril acrescida de antibiótico (ampicilina 50mg/L), macerados e semeados em Agar Sabouraud Dextrose 2\% (SDA) e Agar Sabouraud Dextrose acrescido de cloranfenicol (SDAC) e incubadas a $30^{\circ} \mathrm{C}$ por até 7 dias. A caracterização morfológica foi realizada através da técnica de microcultivo em lâminas e pela coloração com Lactofenol-Azul de Algodão (LPCB).

\section{RESULTADOS}

\section{Levantamento epidemiológico}

Em abril de 2007 foi encaminhado ao LPV-UFMT um ovino Santa Inês, macho, com 3 anos de idade, proveniente de uma propriedade de 30 hectares, no município de Nobres, MT. O ovino apresentava baixo escore corporal, depressão, dificuldade respiratória, corrimento nasal mucoso, exoftalmia unilateral, saliência macia na região temporal e timpanismo 12 horas antes de sua morte. Segundo o proprietário quatro animais, que apresentaram quadro clínico semelhante, morreram na propriedade no período de janeiro a abril, e em anos anteriores a enfermidade não havia ocorrido. Havia histórico de doença similar em anos anteriores, em 2 propriedades vizinhas.

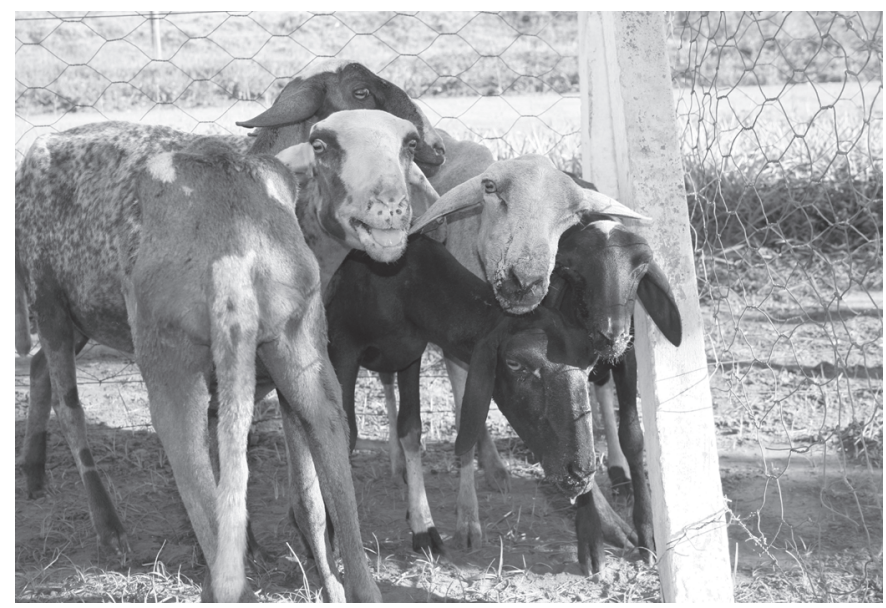

Fig.1. Ovinos com conidiobolomicose apresentando dificuldade respiratória, corrimento nasal muco-sanguinolento e exoftalmia unilateral. 


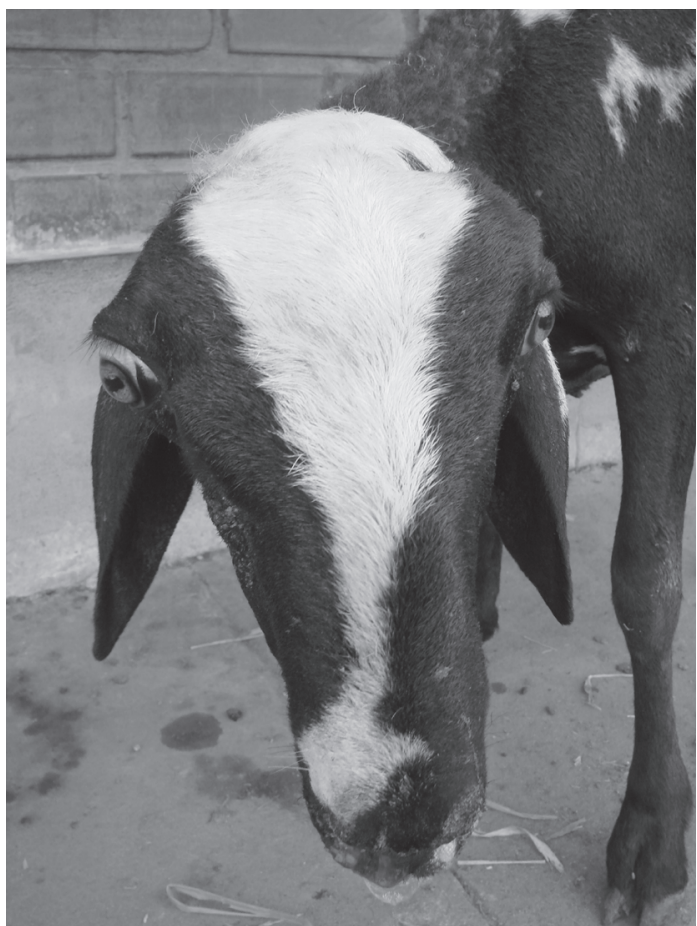

Fig.2. Exoftalmia unilateral e secreção nasal mucosa, em ovino com conidiobolomicose.
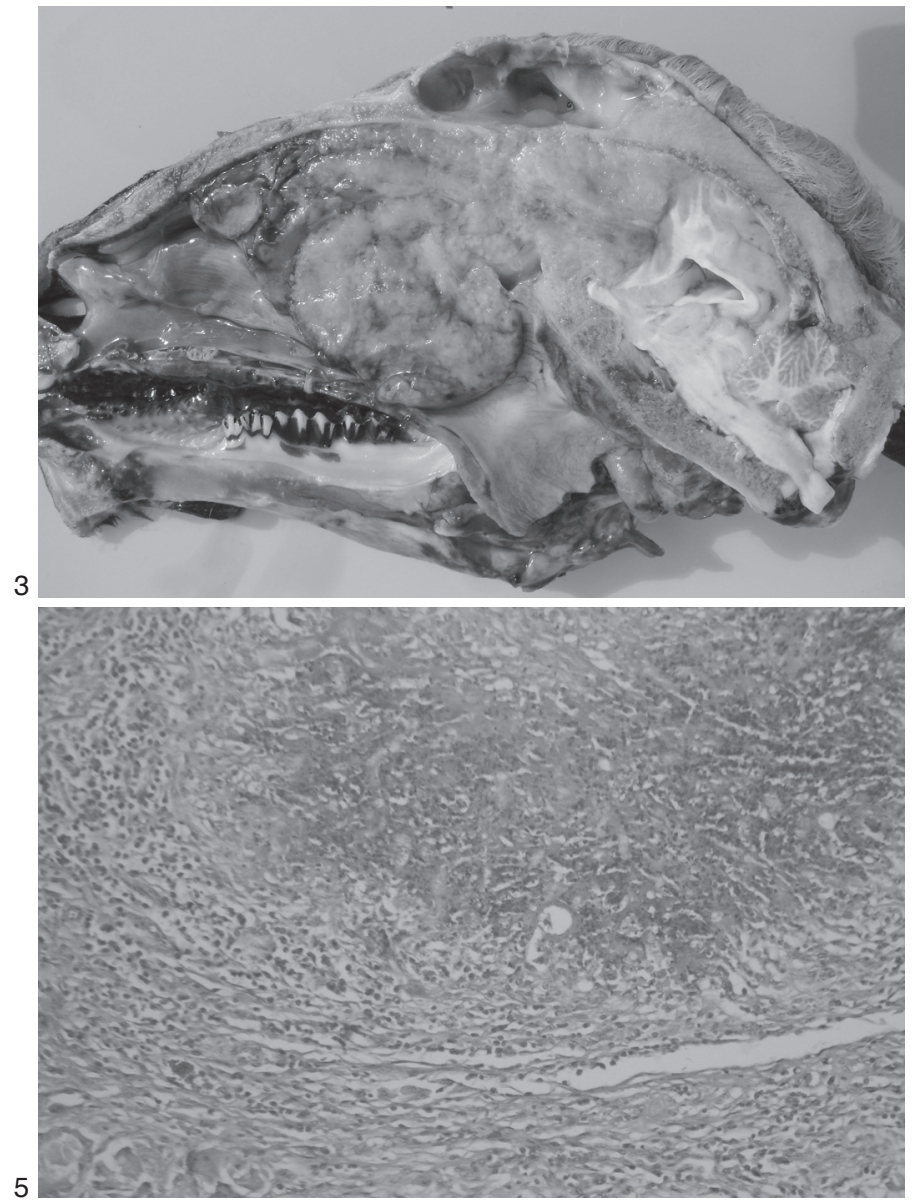

Em visitas a propriedade constatou-se que o rebanho era formado por 40 ovinos adultos, da raça Santa Inês, criados extensivamente em áreas de cerrado formadas por Brachiaria brizantha e áreas úmidas, alagáveis no período das chuvas, invadidas por plantas nativas. Os ovinos bebiam água de poço artesiano e recebiam suplementação mineral. Estavam com quadro clínico da doença, durante a visita, 6 ovinos com idade entre 6 meses e 4 anos (Fig.1), dos quais 3 foram encaminhados ao LPVUFMT e necropsiados após morte espontânea. Outro ovino que havia morrido naturalmente com histórico clinico semelhante foi necropsiado na propriedade. Três ovinos doentes foram tratados com $1 \mathrm{~g}$ de iodeto de potássio por até 15 dias, sem resultados. Deste grupo outro ovino foi necropsiado após 15 dias de uso de iodeto de potássio, seguido de piora clínica com intensa dificuldade respiratória.

\section{Quadro clínico}

De maneira geral os ovinos apresentavam depressão, anorexia, e emagrecimento progressivo. Marcada dificuldade respiratória, com ruídos respiratórios e acentuado corrimento nasal seroso ou muco-sanguinolento foram comuns a todos os ovinos examinados clinicamente. Três ovinos apresentavam marcada exoftalmia unilateral (Fig.2), o globo ocular estava entumecido e em dois ca-

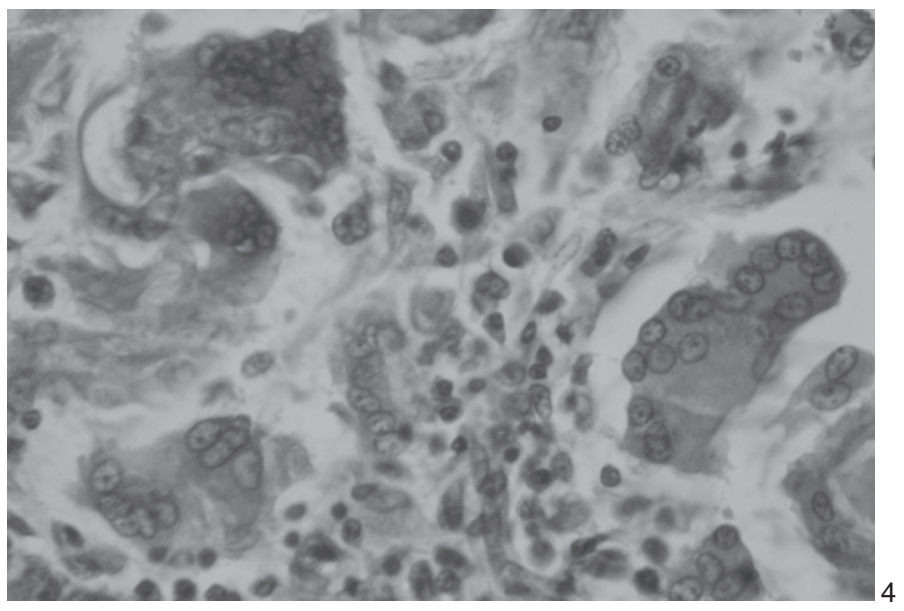

Fig.3. Cabeça de ovino com conidiobolomicose seccionada longitudinalmente, evidenciando massa irregular, branco-amarelada, multilobulada na região etmoidal, invadindo a nasofaringe, se infiltrando sob a lâmina cribiforme, bulbo olfatório e pólo rostral do encéfalo.

Fig.4. Aspecto histológico de tecido da região nasofaríngea com células epitelióides e células gigantes multinucleadas, de ovino com conidiobolomicose. HE, obj.40x.

Fig.5. Região rinofaríngea com inflamação granulomatosa associada a imagens negativas de hifas não septadas circundadas por material Splendore-Hoeppli, de ovino com conidiobolomicose. HE, obj.10x 
sos havia opacidade e úlcera da córnea, conjuntivite, inflamação do globo com corrimento ocular e aparente cegueira unilateral, sendo que um deles tinha miíase no globo ocular. Desvio lateral de cabeça foi notado em um ovino. Intenso timpanismo ruminal ocorreu em um ovino 12 horas antes da morte. Todos os ovinos que adoeceram morreram. A evolução clínica média foi de aproximadamente 30 dias, com variação de 12-56 dias. Não foram observadas alterações no quadro clínico, ou dificuldade para isolamento de Conidiobolus sp. após o uso de 1g/ dia de iodeto de potássio em três ovinos, por 4, 6 e 15 dias respectivamente.

\section{Achados patológicos}

As principais alterações em todos os ovinos necropsiados foram observadas após a secção longitudinal da cabeça. Na região das conchas etimoidais e septo nasal havia variável proliferação de tecido brancacento, irregular, friável, finamente granular e aparentemente lobulado, por vezes com estrias acastanhadas ou avermelhadas ao corte (Fig.3). Em alguns ovinos quase que todos os cornetos eram substituídos por essa proliferação tecidual. Havia também obstrução dos meatos nasais com retenção de exsudato muco-purulento nos seios frontais, proliferação nodular irregular obstruindo as coanas, infiltração na placa cribiforme, na fissura longitudinal do cérebro e bulbo olfatório, nos seios nasais e na órbita ocular causando protusão do globo ocular.

Em 3 ovinos, no pulmão foram encontradas múltiplos nódulos medindo de $0,5-2 \mathrm{~cm}$, amarelados, levemente salientes e translúcidos na superfície pleural, principalmente nos lobos diafragmáticos. Em dois ovinos, os linfonodos regionais estavam tumefeitos e havia áreas amareladas irregulares multifocais, aleatórias na superfície de corte. Dois ovinos apresentavam a forma rinocerebral da conidiobolomicose, caracterizada por infiltração de tecido brancacento, irregular no bulbo olfatório e fissura mediana longitudinal. Em um ovino havia úlcera de abomaso e tumefação de linfonodo regional que ao corte tinha áreas multifocais irregulares e amareladas.

Microscopicamente, nos seis ovinos estudados, nos tecidos de septos nasais, conchas nasais, encéfalo, pulmão, linfonodos, havia áreas multifocias extensas, coalescentes, com intensa proliferação de tecido conjuntivo, infiltrado de neutrófilos, eosinófilos, células epitelióides e células gigantes (Fig.4) freqüentemente circundando áreas de necrose caseosa onde havia imagens negativas de hifas de fungos envoltas em material Splendore-Hoeppli (Fig.5). Hifas ou fragmentos delas eram observados em células gigantes ou livres, não relacionadas com material Splendore-Hoeppli, mas circundadas por células inflamatórias, por vezes discretamente coradas pela eosina. Neovascularização, deposição de colágeno, trombose vascular, congestão e hemorragia eram observadas com freqüência. $\mathrm{Na}$ impregnação pela prata-metanamina (método de Grocott), visualizavam-se hifas largas $(6-25 \mu \mathrm{m}$ de largura), com

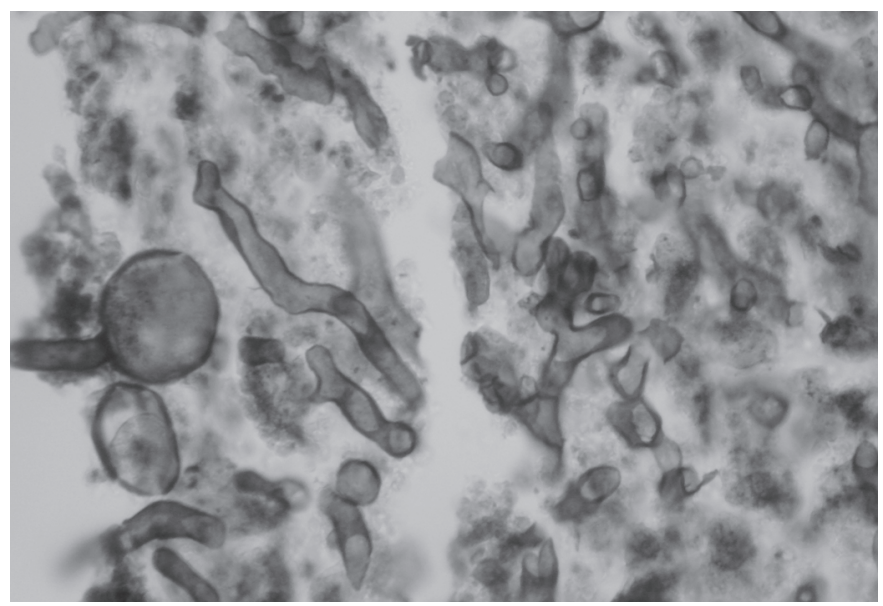

Fig.6. Presença de hifas largas, com parede fina, dilatação balonosa na extremidade e escassos septos, observadas no centro do granuloma, em tecido coletado de ovino com conidiobolomicose. Método Prata-Metanamina (Grocott), obj.100x.

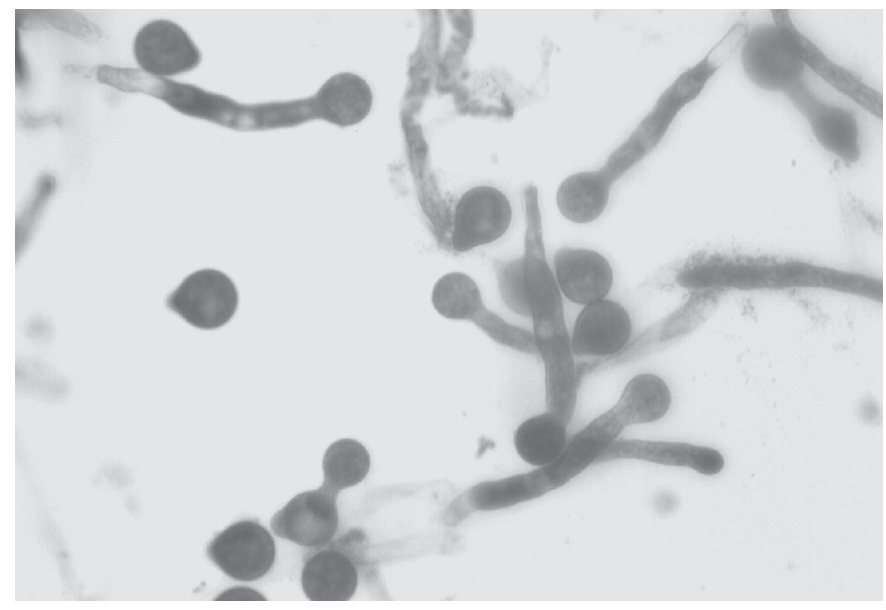

Fig.7. Aspecto microscópico do cultivo a partir de fragmentos de tecido da região nasofaringea de ovino com conidiobolomicose, apresentando conídios esféricos, característicos do gênero Conidiobolus. Lactofenol Azul-de-Algodão, obj.40x.

paredes finas, pobremente septadas e com dilatação balonosa na extremidade (Fig.6). Os contornos destas hifas tinham marcação enegrecida mais evidente que a área central.

\section{Isolamento}

Nos cultivos em SDA foi observado crescimento de colônias planas de coloração creme, lisas nos primeiros dias. Estas colônias tornaram-se rugosas e firmemente aderidas ao ágar após 5 dias. No microcultivo em lâminas coradas com Lactofenol-Azul de Algodão observaram-se hifas com septos escassos e extremidades com dilatações globosas com papilas basais arredondadas proeminentes (Fig.7). Com base nos aspectos morfológicos as estruturas fúngicas foram classificadas no gênero Conidiobolus. 


\section{DISCUSSÃO}

O diagnóstico da conidiobolomicose neste surto de mortalidade de ovinos no Estado de Mato Grosso foi baseado nos achados clínicos, patológicos e principalmente no isolamento de Conidiobolus sp.

A conidiobolomicose freqüentemente é relatada afetando rebanhos de ovinos no Brasil e no mundo (Carrigan et al. 1992, Silva et al. 2007b). Na Austrália C. incongruus foi isolado de ovinos com micose rinofacial e nasofaríngea (Ketterer et al. 1992, Carrigan et al. 1992). Conidiobolus sp. é relatado, também, afetando ovinos em Trinidad Tobago (Morris et al. 2001). No Brasil a enfermidade é descrita na Região Nordeste principalmente nos Estados do Piauí e Paraíba, onde a ovinocultura é mais desenvolvida (Riet-Correa 2007, Silva et al. 2007a,b). Em Mato Grosso a doença tem sido relatada em humanos (Tadano et al. 2005).

A enfermidade em ovinos no Estado de Mato Grosso ocorreu entre janeiro e junho, período com altos índices pluviométricos, elevada temperatura, alta umidade e maior quantidade de matéria vegetal em decomposição, fatores que contribuem para o crescimento do fungo (Prabhu \& Patel 2004). Este fato foi observado também nos levantamentos da enfermidade no estado do Piauí (Silva et al. 2007b). A letalidade observada na propriedade foi de $100 \%$, assim como nos relatos da doença nos surtos na região Nordeste (Silva et al. 2007a).

Os ovinos apresentaram dificuldade respiratória acentuada, corrimento seroso, mucoso e/ou hemorrágico e exoftalmia unilateral, sinais clínicos característicos da conidiobolomicose nasofaríngea descrita em ovinos (Ketterer et al. 1992, Morris et al. 2001, Riet-Correa 2007).

A principal alteração macroscópica nos seis ovinos necropsiados foi proliferação de massa de aspecto nodular na região etmoidal, conchas nasais e nas coanas, que caracteriza a forma nasofaríngea da conidiobolomicose relatada na Austrália (Ketterer et al. 1992) e no Brasil (Silva et al. 2007a). Neste trabalho, lesões extra-nasais relacionadas ao Conidiobolus sp. foram encontradas nos pulmões de três ovinos, no encéfalo de dois, em linfonodos regionais da cabeça de dois e abomaso de um. Lesões semelhantes em outros órgãos são relatados por Ketterer et al. (1992) e Silva et al. (2007a). A forma rinofacial de rinite granulomatosa em ovinos, que deve ser diferenciada dos quadros de conidiobolomicose nasofaríngea, ocorre, também, no Estado de Mato Grosso. Nessa forma da doença as lesões se caracterizam por deformidade facial com necrose e fistulas no palato duro e septo nasal na região média e rostral da cavidade nasal, sendo atribuída a Pythium insidiosum isolado de animais afetados (Santurio et al. 2007).

Neste caso o diagnóstico definitivo da conidiobolomicose foi baseado na visualização de hifas largas $(6-25 \mu \mathrm{m}$ de largura), com escassos septos, de contornos não pa- ralelos, com dilatações globosas na extremidade (10$25 \mu \mathrm{m}$ ), semelhantes ao micélio reprodutivo (conidióforos), estruturas características do gênero Conidiobolus (Larone 1995). Conidiobolus coronatus e $C$. incongruus são freqüentemente isolados nas lesões de conidiobolomicose rinocerebral (Ketterer et al. 1992, Silva et al. 2007a).

\section{REFERÊNCIAS}

Almeid O.P. \& Scully C. 2002. Fungal infections of the mouth. Braz. Oral Sci. 1(1):19-26.

Aydogdu I., Sari R. \& Mizrak B. 2001. Case report. Rhinocerebral zygomycosis. Mycoses 44:59-60.

Carrigan M. J., Small A.C. \& Perry G.H. 1992. Ovine nasal zygomycosis caused by Conidiobolus incongruous. Aust. Vet. J. 69(10):237-240.

Fonseca A.P.M., Fonseca W.S.M., Leal M.J.S. \& Araújo R.C. 1989. Rinoentomoftoromicose: Relato de quatro casos. Anim. Dermatol. 64(5):261-265.

Hoogendijk C.F., van Heerden W.F.P., Pretorius E., Vismer H.F. \& Jacobs J.F. 2006. Rhino-orbitocerebral entomophthoramycosis. Int. J. Oral Maxillofac. Surg. 35:277-280.

Ketterer P.J., Kelly M.A., Connole M.D. \& Ajello L. 1992. Rhinocerebral and nasal zygomycosis in sheep caused by Conidiobolus incongruous. Aust. Vet. J. 69(4):85-87.

Larone D.H. 1995. Medically Important Fungi: A guide to identification. $3^{\text {rd }}$ ed. ASM Press, Washington, DC. 244p.

Morris M., Ngeleka M., Adogwa A.O., Lalla G., St-Germain G. \& Higgins R. 2001. Rhinocerebral zygomycosis in a sheep. Can. Vet. J. 42:227228.

Prabhu R.M. \& Patel R. 2004. Mucormycosis and entomophthoramycosis: a review of the clinical manifestations, diagnosis and treatment. Clinic. Microbiol. Infect. 10(1):31-47.

Prophet E.B., Mills, B., Arrington J.B. \& Sobin L.H. 1992. Laboratory Methods in Histotechnology. 1st ed. Armed Forces Institute of Pathology, Washington, D.C. 279p.

Rane S.R., Jayaraman A., Puranik S.C., Deshmukh S.D. \& Bapat V.M. 2002. Entomopthoromycosis: Report of four cases. Indian J. Dermatol. Venereol. Leprol. 68:296-297.

Riet-Correa F. 2007. Conidiobolomicose em ovinos. In: Riet-Correa F., Schild A.L., Lemos R.A.A. \& Borges J.R.J. (ed.), Doenças dos Ruminantes e Eqüinos. 3aㅡ. ed. Palloti, Santa Maria, RS, p.448-450.

Santurio J.M., Argenta J.S., Schwendler S.E., Cavalheiro A.S., Pereira D.I.B., Zanette R.A., Alves S.H., Dutra V., Silva M.C., Arruda L.P., Nakazato L. \& Colodel E.M. 2007. Granulomatous rhinitis in sheep associated with Pythium insidiosum infection. Vet. Rec. (Submitted for publication)

Silva S.M.M.S., Castro R.S., Costa F.A.L., Vasconcelos A.C., Batista M.C.S., Riet-Correa F. \& Carvalho E.M.S. 2007a. Conidiobolomycosis in sheep in Brazil. Vet. Pathol. 44:314-319.

Silva S.M.M.S., Castro S.C., Costa F.A.L., Vasconcelos A.C., Batista M.C.S., Riet-Correa F., Carvalho E.M.S. \& Lopes J.B. 2007 b. Epidemiologia e sinais clínicos da conidiobolomicose em ovinos no Estado do Piauí. Pesq. Vet. Bras. 27(4):184-190.

Tadano T., Paim N.P., Hueb M. \& Fontes C.J.F. 2005. Entomoftoromicose (zigomicose) causada por Conidiobolus coronatus em Mato Grosso (Brasil): relato de caso. Revta Soc. Bras. Med. Trop. 38(2):188190.

Thomas M.M., Bai S.M., Jayaprakash C., Jose P. \& Ebenezer R. 2006. Rhinoentomophthoromycosis. Indian. J. Dermatol. Venereol. Leprol. 72(4):296-299. 